\title{
Oral Bovine Serum Concentrate Improves Cryptosporidial Enteritis in Calves
}

\author{
ELAINE HUNT, QIANG FU, MARTHA U. ARMSTRONG, DERRALYN K. RENNIX, \\ DAVID W. WEBSTER, JOSEPH A. GALANKO, WUNIAN CHEN, ERIC M. WEAVER, \\ ROBERT A. ARGENZIO, AND J. MARC RHOADS
}

\author{
Department of Anatomy, Physiology, and Radiological Sciences, North Carolina State University College \\ of Veterinary Medicine, Raleigh, NC, U.S.A. [E.H., M.U.A., D.K.R., D.W.W., R.A.A.]; Department of \\ Pediatrics [Q.F., W.C., J.M.R.] and School of Public Health [J.A.G.], University of North Carolina, \\ Chapel Hill, NC, U.S.A.; Center for Gastrointestinal Biology and Disease [J.A.G., R.A.A., J.M.R.], Chapel \\ Hill, NC, U.S.A.; Proliant, Inc., Ames, IA, U.S.A. [E.M.W.]
}

\begin{abstract}
Cryptosporidium parvum produces a prolonged watery diarrhea unresponsive to conventional antimicrobials. Because of reported efficacy of antibody-based immunotherapy, we studied the effect of inexpensive, commercially available oral bovine serum concentrate (BSC) in experimental cryptosporidiosis. Twenty-four calves were treated with $57 \mathrm{~g} / \mathrm{d}$ BSC $(n=12)$ or soy protein $(n=12)$ added to their standard whey protein-based milk replacer ( $227 \mathrm{~g} / 2 \mathrm{~L}$ twice daily). Of the 24,9 were also treated with L-glutamine (GLN), $8 \mathrm{~g} / \mathrm{L}(50 \mathrm{mM})$ in the milk $(5$ calves in the BSC group and 4 in the soy group). Animals were inoculated with $10^{8}$ cryptosporidium oocysts per os on d 8 of life and received oral rehydration on $\mathrm{d} 12-14$. Eight uninfected controls were treated with BSC or soy protein. Fecal and urine volume and urinary Cr-EDTA excretion were measured. Animals were killed on d 18 of life. Cryptosporidiosis induced severe watery diarrhea lasting $>9 \mathrm{~d}$ and produced a $25 \%$ increase in intestinal permeability, a $33 \%$ decrease in villous surface area,
\end{abstract}

\section{ABSTRACT}

and a $40 \%$ reduction in mucosal lactase specific activity. Glutamine treatment had no effect on the diarrhea or any of the intestinal tests; and therefore pooled data were used to compare the 12 calves treated with BSC with the 12 treated with soy. In animals receiving $\mathrm{BSC}$, peak diarrheal volume and intestinal permeability were reduced $33 \%$, fewer oocysts were shed, intestinal crypts were significantly deeper, and villous surface area returned to normal by $9 \mathrm{~d}$ after infection (all $p \leq 0.05$ ). BSC should be studied as a treatment for human cryptosporidiosis.

(Pediatr Res 51: 370-376, 2002)

\section{Abbreviations}

BSC, bovine serum concentrate

EGF, epidermal growth factor

Ig, immunoglobulin

TGF, transforming growth factor
Cryptosporidiosis is a major enteric pathogen found globally in infants with acute and chronic diarrhea, and is a cause of persistent diarrhea in 10\%-20\% of patients with AIDS. Cryptosporidium parvum is also the most widespread enteropathogen identified in neonatal calves. Ninety percent of American dairy farms harbor this coccidian, and $92 \%$ of asymptomatic adult cows have specific anti-C. parvum IgG, IgG1, IgG2, and IgM antibodies (1). Neonatal calves experience high morbidity, but low mortality with monoinfections, although mixed infections result in a much greater rate of mortality (2). The epidemic potential of this organism was realized in Milwaukee in 1993, when over 400,000 residents contracted the infection from contaminated municipal water sources (3). Presently,

Received November 17, 2000; accepted May 4, 2001.

Correspondence: J. Marc Rhoads, Department of Pediatrics, University of North Carolina, Campus Box 7220, Chapel Hill, NC 27599-7220, U.S.A.; e-mail: rhoads@med.unc.edu

This study was supported by Proliant Inc., Ames, IA, U.S.A. there is no available antimicrobial to kill cryptosporidium; in fact, there is no treatment to stimulate bowel repair from any infectious agent in infants with serious or chronic diarrhea.

We have shown that cryptosporidial diarrhea is both malabsorptive and secretory in nature, produced by partial mucosal destruction as well as elevated levels of prostaglandin $\mathrm{E}_{2}$ and prostacyclin, the latter of which activate enteric secretomotor neurons (4). We have also found beneficial effects of growth factors (present in serum and colostrum) in enhancing bowel repair in rotavirus diarrhea and after intestinal ischemic injury $(5,6)$. Recently, Lembcke (7) showed in Peruvian children recovering from acute diarrhea that BSC treatment improved fat and energy absorption compared with standard oral rehydration therapy. Because serum contains specific growth factors and stimulates cultured intestinal cell proliferation and migration (8), and because most cows have specific antibodies to C. parvum (1), we proposed that BSC will reduce the 
severity of cryptosporidiosis and enhance bowel repair in cryptosporidiosis.

The principal aim of these studies was to determine whether bovine serum concentrate enhances bowel repair in acute bovine cryptosporidial enteritis. We also determined whether BSC facilitated clearance of cryptosporidium, which would be of great benefit in immunocompromised patients.

\section{METHODS}

Animals and challenge. Experimental bull calves $(n=32$, approximately $50 \mathrm{~kg}$ ), isolated at birth from the herd and fed colostrum by the vendor farm, were obtained by $2 \mathrm{~d}$ of age. The basic calf diet was a commercially available $23 \%$ whey protein-based milk replacer (Purina, St. Louis, MO, U.S.A.). Calves were fed $454 \mathrm{~g}$ dry matter daily $[227 \mathrm{~g}$ in two feedings, except during oral rehydration solution (ORS) feeding] delivered in two 2-L feedings offered in the morning and evening. On d 2-7, calves were fed $170.3 \mathrm{~g}$ milk replacer (23\% protein) blended with 56.7 g BSC (Proliant Inc., Ames, IA, U.S.A.) or $56.7 \mathrm{~g}$ soy protein (Ardex AF by Archer Daniels Midland, Decatur, IL, U.S.A.). On d 8-10, calves were fed two feedings of ORS blended with $56.7 \mathrm{~g}$ BSC or soy protein. On d 11-13, calves were returned to the initial feeding regimen. Calves were assigned to one of six treatment groups, as follows:

1. uninfected control + isolated soy protein $(n=4)$

2. uninfected control $+\operatorname{BSC}(n=4)$

3. infected + soy protein $(n=8)$

4. infected $+\operatorname{BSC}(n=7)$

5. infected + soy protein + L-glutamine $(9 \mathrm{~g} / \mathrm{L})(n=4)$

6. infected $+\mathrm{BSC}+$ L-glutamine $(9 \mathrm{~g} / \mathrm{L})(n=5)$

Cr-EDTA was given at a constant dose of $90 \mathrm{mg}$ in all feedings and was measured in the daily urine as an indicator of intestinal damage and permeability (9). All diet components were premeasured and mixed just before feeding with $2 \mathrm{~L}$ warmed water. Calves were maintained on the assigned diets for $7 \mathrm{~d}$ before infection to establish steady state Cr-EDTA conditions (see below). All calves were fed via a nipple-bottle feeder their assigned treatment twice per day for $17 \mathrm{~d}$.

Plasma proteins are commonly collected from abattoirs under hygienic conditions for use in specialty food products, biologicals, animal health, and pharmaceuticals. The U.S. Department of Agriculture (USDA) regulates the collection and processing of plasma proteins for edible uses. The bovine serum used in this study was inspected and approved for edible use. Briefly, calcium chloride is added to chilled plasma to activate the conversion of fibrinogen to fibrin. The fibrin is removed by centrifugation and the resulting serum (defibrinated plasma) is concentrated using ultrafiltration. The concentrated serum protein fraction is then spray-dried to maintain the functional characteristics of the proteins. Dried BSC is a fine, tan-colored powder containing approximately $80 \%$ protein, of which $60 \%$ is albumin and $25 \%$ is IgG. We have also measured significant levels of IGF-I (6000 ng/g protein) and TGF- $\beta 1$ (90 $\mathrm{ng} / \mathrm{g}$ ) in BSC.

For the first $6 \mathrm{~d}$, calves were housed in individual pens and received twice daily health exams and the assigned feedings. On $\mathrm{d} 7$, calves were housed in an isolation room in individual metabolic cages that allowed the separation and collection of urine and feces. These output collections were weighed every $24 \mathrm{~h}$, and the urine was sampled and saved for subsequent $\mathrm{Cr}$ analysis by flame atomic absorption spectrometry. Physical exams and fecal smears (for $C$. parvum grading) were continued daily. All data collected through the $\mathrm{d} 7$ were considered baseline before infection with C. parvum.

On d 8 of age, calves received either $10^{8}$ oocysts of $C$. parvum orally by bottle feeding or a sham inoculum of PBS substrate. C. parvum oocysts isolated from feces of infected calves were purchased from Pleasant Hill Farms (Troy, ID, U.S.A.) and were used within $12 \mathrm{wk}$ of purchase. The Iowa isolate of $C$. parvum was originally obtained from $\mathrm{H}$. Moon (Ames, IA, U.S.A.). Physical exams, fecal smears, and feedings were continued daily for the next $9 \mathrm{~d}$ postinfection. On $\mathrm{d}$ 4, 5, and 6 postinfection, both control and infected calves received oral rehydration supplement (Resorb, Pfizer, Exton, PA, U.S.A.) replacing the milk substrate but including the $57 \mathrm{~g}$ of assigned treatment and $90 \mathrm{mg}$ of Cr-EDTA. On postinfection d 9, calves were killed with i.v. sodium pentobarbital ( 90 $\mathrm{mg} / \mathrm{kg}$ after sedation with xylazine $0.1 \mathrm{mg} / \mathrm{kg}$ ). Mucosal sections of ileum were taken for lactase activity determination and histologic analysis.

Fecal scores. Stools were scored as follows: 1+: solid stools; $2+$ : mildly loose stools; $3+$ : thick liquid stools; $4+$ : watery diarrhea.

Oocyst shedding was quantified $(1+-4+)$ as reported previously by the auramine 0 staining technique using a Zeiss fluorescent microscope (Zeiss, Welwyn Garden City, U.K.) (10).

Histology and morphometric analysis. Segments of ileum, the site of peak intestinal damage in cryptosporidiosis (9), were fixed in situ by intraluminal injection of a $10 \%$ formalin solution. The fecal material was gently removed and the segment immersed in fixative. Formalin-fixed segments were embedded in paraffin and 5 - $\mu$ m-thick sections were cut and stained with hematoxylin and eosin for examination by light microscopy. Computer-assisted morphometric measurements were conducted with a video-imaging system (Nikon-FXA, Nikon, Melville, NY, U.S.A.). All samples were measured twice by each of two observers masked to the treatment group. Three to six well-oriented villi from sections of ileum (without underlying Peyer's patches) were measured at $100 \times$ magnification to determine mean villous height and width. Crypt depth was measured from three to four sites from the same sections. Villous surface areas for representative villi were calculated as reported previously (10).

Assays of mucosal lactase. Intestinal lactase specific activity was measured by the technique of Dahlquist et al. (32) as previously described (11). Mucosa was scraped from the jejunal segments on a pane of glass over ice, using a glass slide; the scrapings were homogenized in iced buffer $(0.25 \mathrm{mM}$ lactose, $0.2 \mathrm{M}$ Tris, $0.15 \mathrm{M}, \mathrm{KC} 1,2.5 \mathrm{mM}$, EDTA, pH 7.4 at $\left.4^{\circ} \mathrm{C}\right)$. The homogenates were immediately frozen in aliquots at $-70^{\circ} \mathrm{C}$ and were assayed within 2-3 wk. Five samples in the soytreated group and three samples from the BSC-treated group were lost because of malfunction of the laboratory freezer. 
Statistics. We used a one-sided Wilcoxon test to determine whether there was any advantage of BSC compared with soy protein. The Wilcoxon test is a nonparametric test used to determine whether two groups are significantly different while not making assumptions about the distribution of the data. Data are expressed as means $\pm \mathrm{SE}$.

These studies were approved by the North Carolina State University College of Veterinary Medicine Committee to Review Applications for Vertebrate Animal User.

\section{RESULTS}

Diarrheal output. Although none of calves died, moderate diarrhea was observed in each calf investigated (score $3+$ out of $4+$ by visual analog score) at d 4-6. Diarrhea was mild (score $2+$ ) for the first $3 \mathrm{~d}$, became moderate (score $3+$ ) for $3 \mathrm{~d}$, with a mean daily volume of approximately 0.5 $\mathrm{L})$, and then became mild again in both treatment groups between $\mathrm{d} 7$ and 9 .

Glutamine treatment had no significant effect on diarrheal volume. For example, calves treated with BSC with glutamine had $3.9 \pm 1.5$ total liters of stool, whereas calves treated with BSC without glutamine had $4.0 \pm 0.7 \mathrm{~L}$ of stool. Additionally, analysis of intestinal mucosal histology revealed no significant differences in villous surface area or crypt depth in glutamine-treated calves, and glutamine had no beneficial effect on Cr-EDTA permeability. Therefore, all data presented reflect pooled data of BSC-treated compared with soy protein-treated groups.

BSC-treated calves had approximately a 33\% reduction in volume of diarrhea $(p \leq 0.05)$ at the peak of illness (d 4-6 postinoculation)(Fig. 1), compared with soy protein-treated calves, although stools remained looser than normal and volume was about twofold greater than normal at the end of the study in both groups. There were no significant differences in urine output, comparing the two treatment groups.

Intestinal permeability. Comparing uninfected animals supplemented with soy protein or BSC, there was no difference in permeability to chromium. BSC produced approximately a

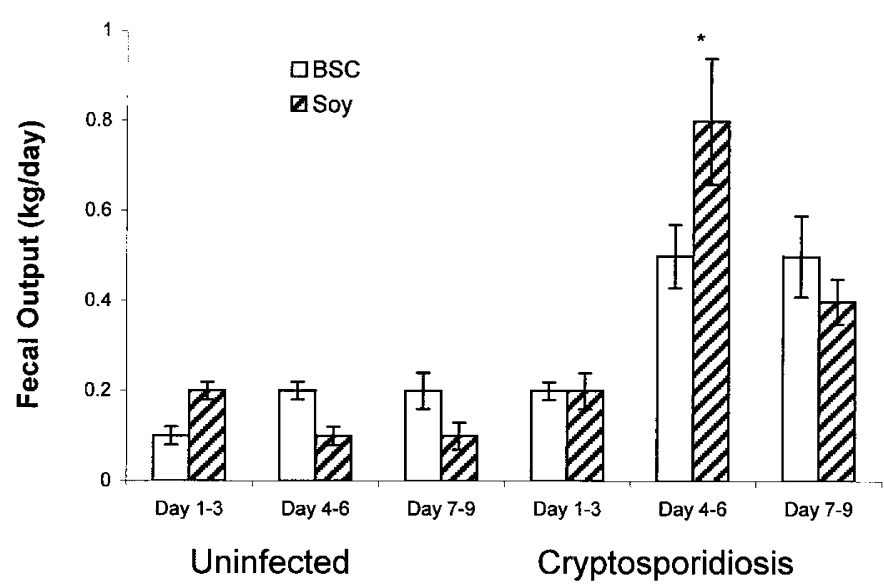

Figure 1. Diarrheal output per animal on d 1-3, 4-6, and 7-9 postinoculation. Soy protein-supplemented group is shown in striped bars; BSC-treated group is shown in open bars. Means \pm SEM. ${ }^{*} p=0.03$ comparing soy protein and BSC-supplemented groups ( $n=12$ in each group).
$30 \%$ decrease in total gut permeability at d $4-6$ after inoculation, compared with permeability in soy-treated infected animals, as measured by urinary excretion of ingested chromium ( $p \leq 0.001)$. Additionally, infected calves treated with BSC (at d 1-3 postinoculation) demonstrated reduced permeability ( $p=0.02$, Fig. 2 ) compared with the uninfected soytreated and BSC-treated control groups.

Ileal morphology. Figure 3 shows representative histologic samples from ileum of normal and cryptosporidium-infected calves. We measured villus height, villus width, and crypt depth from all samples. Because villous surface area gives a more accurate picture of absorptive surface than villous height in cryptosporidiosis, where villus blunting is partial, we calculated villous surface area using an equation we previously published in a study of piglet cryptosporidiosis (10). Figures 3 and $4 A$ depict an approximately $15 \%$ increase in villus surface area of ileum from infected calves fed BSC compared with soy-supplemented controls $(p=0.05$ comparing soy- and BSC-treated groups). We also measured ileal crypt depth as an index of the proliferative response to infection and BSC treatment. Crypt depth of the ileum of infected calves at $9 \mathrm{~d}$ postinoculation was significantly increased, comparing BSC with soy protein treatment (Figs. 3 and $4 B$ ), with a $15 \%$ increase in crypt depth in the BSC-treated group compared with the soy group $(p \leq 0.05)$. The number of histologic samples used for villus/crypt measurement differed from the number of animals enrolled in the study because several histologic samples had no measurable villi that were Peyer's patch-free. (Note that villi above Peyer's patches are shorter than villi from patch-free mucosa.)

Lactase specific activity. BSC enhanced the specific activity of intestinal lactase in infected calves ( $p \leq 0.05$, comparing BSC-treated with soy protein-treated groups, Fig. 5). No significant difference in ileal lactase activity was found comparing normal calves treated with soy protein with those receiving BSC. Soy-treated infected calves had a 30\% lower ileal lactase-specific activity than soy-treated controls $(p=0.03)$ at $\mathrm{d}$ 18 of life. This provided evidence that cryptosporidiuminfected ileum had not fully recovered by d 9 postinoculation.

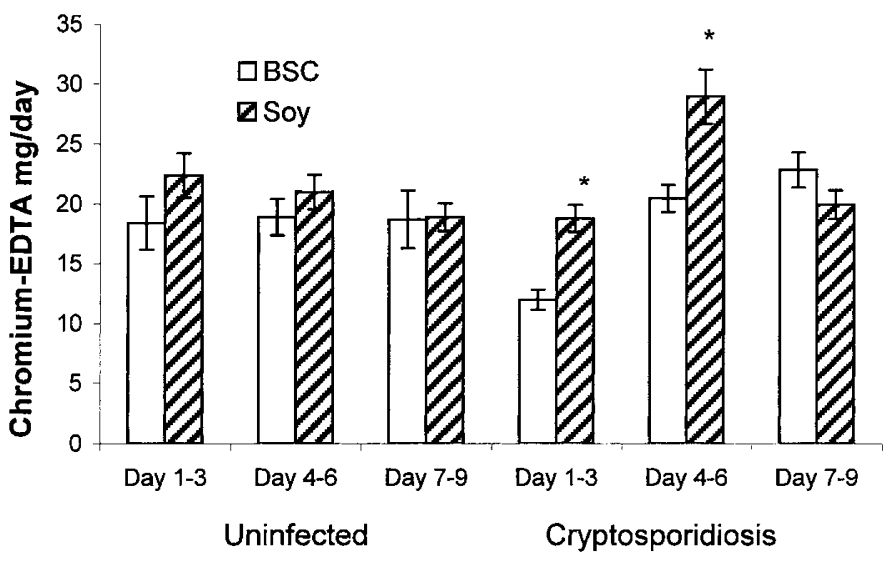

Figure 2. Urinary chromium excretion as a measure of intestinal permeability in BSC- and soy-treated groups in 3-d intervals of the study. Soy proteinsupplemented group is shown in striped bars; BSC-treated group is shown in open bars. Means \pm SEM. ${ }^{*} p \leq 0.01$ comparing the two groups on indicated day. 

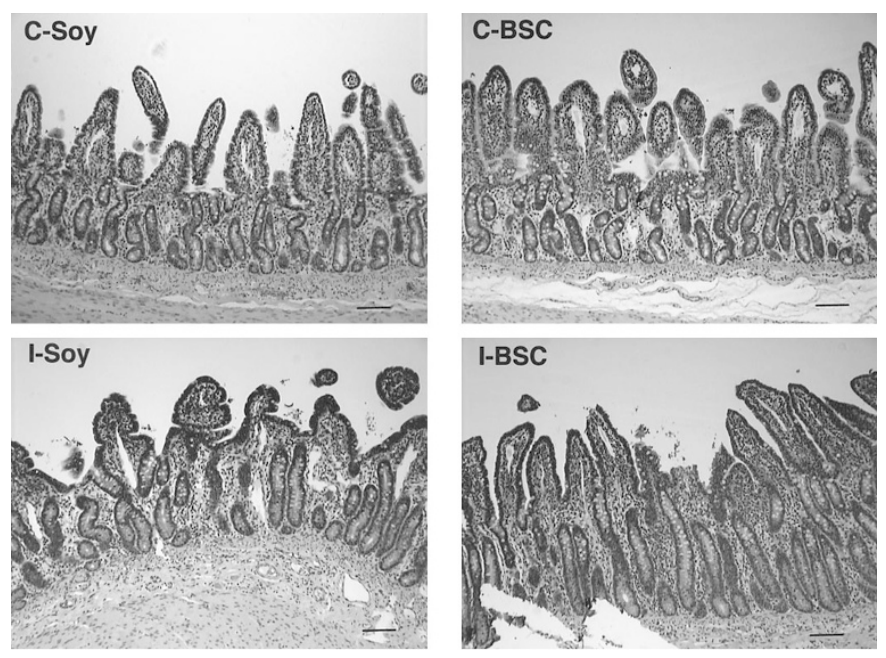

Figure 3. Ileal mucosa of normal and 9-d cryptosporidium-infected calves (hematoxylin and eosin; scale bar represents $10 \mu \mathrm{m}$ ). $C$-Soy: Ileum of control 18 -d-old calf treated with soy protein supplement. $C$ - $B S C$ : Ileum of control calf treated with BSC. I-Soy: Infected ileum, soy-treated group. I-BSC: Infected ileum of calf treated with BSC. Ileal villi of BSC-treated infected calves were taller and thinner, consistent with less inflammation. Ileal crypts of BSCtreated infected calves were deeper than those of soy-treated controls.

Oocyst shedding. In addition to growth factors, BSC contains Ig (as measured by radial immunodiffusion), which could reduce the duration or severity of infection. BSC reduced cryptosporidial oocyst shedding almost four fold at d 4-6 postinoculation ( $p=0.03$, Fig. 6). However, at other time points, including at the end of the study, the mean number of oocysts per high-power field and per stool volume was unchanged compared with controls. Animals from all treatment groups continued to shed oocytes at the end of the study, even though they were recovering from the diarrhea.

\section{DISCUSSION}

Cryptosporidium is a major threat to humans, producing prolonged episodes of acute diarrhea in infants, especially in daycare center outbreaks, and life-threatening watery diarrhea in immunocompromised teens and adults $(12,13)$. HIVinfected patients have been reported with infections lasting years and fecal volumes averaging $1.5 \mathrm{~L} / \mathrm{d}$ (13). There is no antimicrobial agent proven to be effective in treating cryptosporidiosis. We chose to study a calf model of this infection. In this host at 1 wk of age, $85 \%$ of suckling calves and $52 \%$ of dairy calves excrete the parasite, and about half of these have diarrhea (14).

We proposed that $\mathrm{BSC}$ would be effective in treating this infection, because hyperimmune bovine colostrum has been previously shown to protect from infection and to produce a partial resolution of symptoms in infected individuals (15). Additionally, even though hyperimmunized cows were not used to prepare the BSC, most adult cattle have detectable antibody to $C$. parvum (1; Perryman LE, personal communication, August 2000). BSC is inexpensive, commercially available, and approved by the USDA for use as a food ingredient. BSC is currently available as a dietary supplement (Immunolin or NutraGammax) in health food stores. Spray-drying of BSC
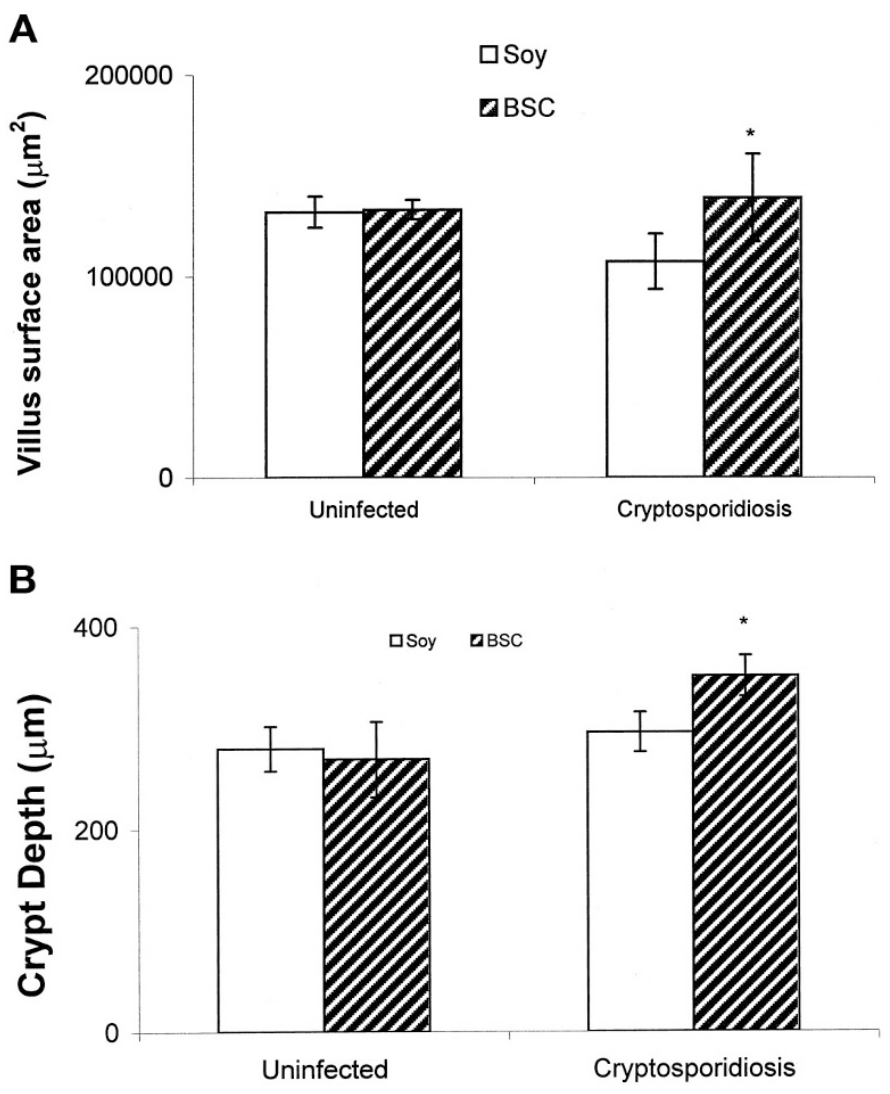

Figure 4. (A) Calculated villus surface area of ileum from normal and infected calves (with soy or BSC treatment) at d 9 postinoculation. ${ }^{*} p=0.05$ comparing soy group with BSC group of infected calves $(n=4$ in each uninfected group, $n=8$ in each infected group). Numbers of calves studied are the same for villous surface area and crypt depth. $(B)$ Crypt depth of ileum from normal and infected calves (with soy or BSC treatment) at d 9 postinoculation. ${ }^{*} p<0.05$ comparing soy group with BSC group of infected calves. Soy protein-supplemented group is shown in open bars; BSC-treated group is shown in striped bars.

protects the structure of $\operatorname{IgG}, \operatorname{IgM}$, and $\operatorname{IgA}$, but also of transferrin, albumin, TGF- $\beta$, and IGF-1. BSC has been used to assist the recovery of children with acute enteritis and is currently under investigation as a dietary additive to prevent infection in children at high risk for diarrheal disease (Brown KH, personal communication, September 1999).

BSC has also been shown to increase efficiency of dietary protein utilization in newborn piglets (16). Soy protein supplementation was chosen to control for possible nutritional effects of BSC because human studies have demonstrated equivalent growth in babies fed cow milk and soy milk-based formulas (17). As mentioned, slightly inferior rates of growth in exclusively soy-fed calves have been observed $(18,19)$, but in the current study we used bovine whey protein in the basal diet with soy or BSC added as a supplement, and the duration of the study was only $9 \mathrm{~d}$. Thus, soy protein is a nutritionally similar supplement for comparison with BSC.

In our study, BSC successfully diminished fecal losses, reduced gut permeability, and enhanced ileal crypt depth and villous surface area. The diarrhea was moderate, with mean fecal volume at the peak of infection of $500 \mathrm{~g} / \mathrm{d}$ in BSC-treated infected calves, $800 \mathrm{~g} / \mathrm{d}$ in soy-fed calves, and $200 \mathrm{~g} / \mathrm{d}$ in the 
preinfection baseline period. None of the calves died during the study. BSC not only improved the diarrhea but also reduced gut permeability and enhanced crypt depth and villous surface area after infection.

There are three potential mechanisms for the efficacy of BSC in reducing the severity of bovine cryptosporidiosis. First, Ig in the BSC may have facilitated a reduction in number of viable parasites. Previous studies in human cryptosporidiosis have shown efficacy of immune bovine colostrum in some studies (20) and lack of efficacy in others (21). In our study, reduced oocyst shedding in BSC-treated calves was seen, but oocysts remained in the stool at the end of the study. Previous animal studies showed that colostral antibodies detected in feces are not protective. In feces from infected animals treated with colostrum, anti-C. parvum, detectable IgA levels rose between d 7 and 14 postinfection (22). These coproantibodies coincided with falling oocyst output, but fecal antibodies were protective only at late time points after infection (16 wk later). BSC is defibrinated, dialyzed, and spray-dried but is not heated above $63^{\circ} \mathrm{C}$, resulting in preservation of its Ig. One of our collaborators attempted to measure $\mathrm{BSC}$-specific reactivity to sporozoite/oocyst proteins by ELISA, but ran into difficulties with dried immunoglobulins producing a high background activity. We have consistently measured titers to Escherichia coli and other bacteria and rotavirus, and have observed in vitro toxin neutralization by BSC, but BSC does not neutralize cryptosporidium and did not prevent infection in our study. In a recent study of BSC treatment of piglets inoculated with porcine rotavirus, BSC treatment did not affect virus shedding into the feces, but completely prevented the diarrhea; BSC treatment produced taller jejunal villi and greater intestinal lactase activity (23). These findings rule against an immunologic effect of BSC as the mechanism of efficacy in rotavirus enteritis.

Second, BSC could have facilitated intestinal repair via growth factors present in bovine serum. We demonstrated decreased intestinal permeability and increased crypt depth in the ileum of BSC-treated infected calves. In infectious enter-

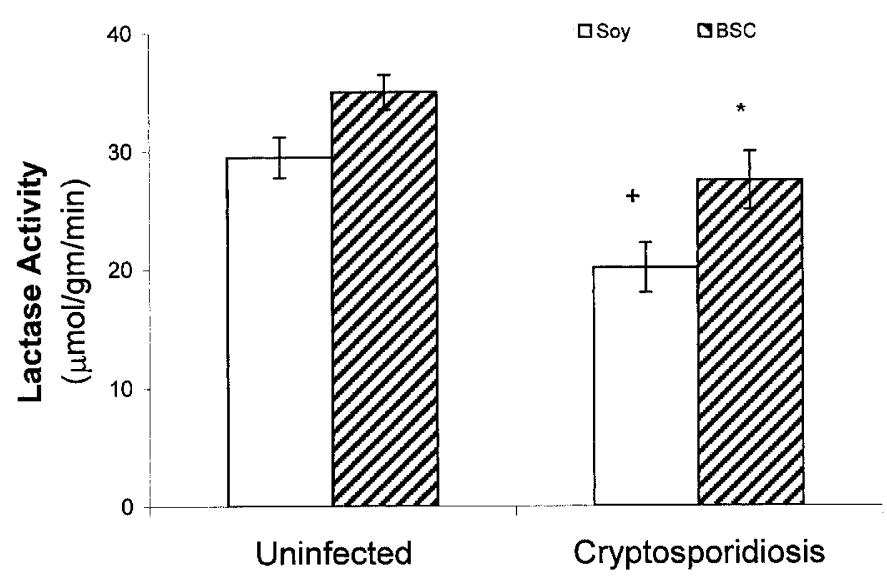

Figure 5. Ileal lactase activity from normal and cryptosporidiosis infected calves. ${ }^{*} p \leq 0.05$ comparing $\mathrm{BSC}$ and soy-treated groups. ${ }^{+} p \leq 0.05$ comparing soy-treated uninfected and infected groups. ( $n=4$ in each uninfected group, $n=7$ from BSC-infected group, $n=9$ from soy-infected group). Soy protein-supplemented group is shown in open bars; BSC-treated group is shown in striped bars. opathies, stem cells in the intestinal crypts undergo mitosis to regenerate the damaged villi. In a rat intestinal cell line (IEC6), we have found that BSC enhances the rate of thymidine incorporation and the rate of proliferation-independent cell migration across de-epithelialized surfaces, each about twofold compared with control responses without serum (8). This effect is partially inhibited by anti-TGF $\beta$ antibody (8). Such increases in epithelial cell migration could explain the decreased intestinal permeability to Cr-EDTA in vivo. Antibodies to IGF-1 and TGF $\beta$, both of which stimulate intestinal cell migration, partially neutralize this in vitro effect of BSC (Chen W, Rhoads JM, unpublished observation). Interestingly, human volunteers who ingested $C$. parvum were found to have enhanced TGF $\beta$ mRNA expression in the small intestine at the onset of and during diarrhea (24). Of even more direct relevance to our findings with BSC, which contains $\operatorname{TGF} \beta$, Roche et al. (25) recently found that, when TGF- $\beta$ was applied to intestinal epithelial cell monolayers, this growth factor prevented the increase in permeability seen when monolayers were subsequently experimentally infected with cryptosporidium.

A third potential mechanism for reduced severity of infection is that the BSC could have interfered with cryptosporidial attachment, reducing invasion and replication. This mechanism was not addressed in the present study, but the observation that Cr-EDTA permeability decreased on d 1-3 postinfection in the BSC-treated group suggest that parasites did attach early, resulting in villus damage. The observation that small numbers of cysts persisted in the stool in both treatment groups $9 \mathrm{~d}$ after inoculation also suggests that oocysts remained in the intestine during the experimental period.

The results of the present study compare favorably with previous animal studies of oral therapy with growth factors and/or nutrients for animal models of infant diarrhea. There have been multiple negative studies of enteral treatment for acute diarrhea, including studies from our group of glutamine, polyamines, fructo-oligosaccharides, and rice powder in piglets

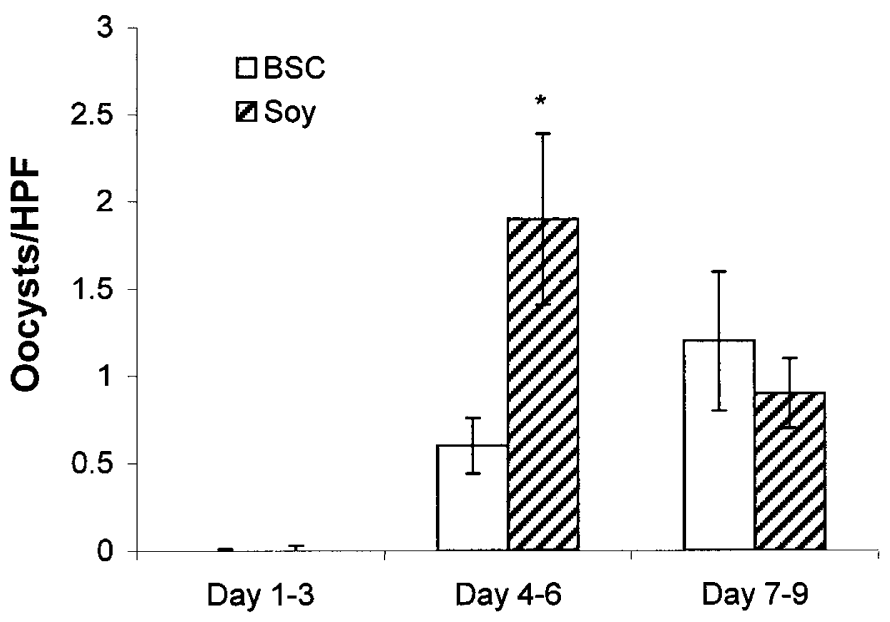

Figure 6. Number of cryptosporidial oocysts per high-power field $(40 \times)$ on fecal microscopy, plotted as counts per 3-d interval after infection. *Indicates a significant reduction in oocyst counts on $\mathrm{d} 4-6$ postinoculation $(p \leq 0.05$, $\mathrm{n}=12$ in each group). Soy protein-supplemented group is shown in open bars; BSC-treated group is shown in striped bars. 
with rotavirus infection (26). In rabbit and piglet models of viral enteritis, EGF and TGF $\alpha$ stimulated villus height but did not reduce diarrheal volume $(27,28)$. In a more severe model, piglet ischemia-injured ileum, we found that glutamine plus TGF $\alpha$ stimulated mitogen-activated protein kinases and villous repair (6). We are not aware of reports of reduced gut permeability in vivo after treatment with EGF or TGF $\alpha$ during acute diarrhea, as seen with BSC in the current studies. Additionally, BSC had potent effects on recovery from diarrhea in a preliminary report of piglet rotavirus diarrhea (23).

In our studies, BSC treatment appears to have reduced intestinal permeability compared with infected soy-treated controls and compared with uninfected controls. There are at least two opposing factors contributing to this effect. One is a decrease in surface area caused by infection, which would reduce the number of paracellular pathways in the epithelium and reduce permeability across infected tissue. This does not explain why permeability is reduced in the BSC-treated group compared with the infected soy-treated group. The opposing factor is probably enhanced restitution in the BSC-treated group. Thus, the unaffected permeability in the soy group on $\mathrm{d}$ 1-3 reflects the decreased surface area superimposed on an increased permeability due to parasite damage, with the two effects canceling. In the BSC group, decreased surface area plus increased restitution would be additive and would decrease ileal permeability. In support of this explanation, in studies of intestinal cell monolayers, Guerrant's group has shown increased conductance after cryptosporidial infection (25), whereas in whole tissue we have consistently found that the conductance decreases after cryptosporidial infection produces a reduction in mucosal surface area (10).

Despite numerous human trials of oral therapy for infant diarrhea, very few treatments have been shown to reduce the volume or duration of diarrhea, and none has been shown to improve intestinal histology. Rice-based oral rehydration solutions have been shown to reduce diarrheal volume approximately $33 \%$ in patients with secretory diarrhea, such as cholera and enterotoxigenic E. coli (29). However, in infantile diarrhea, rice-based ORS has not been shown to have a significant effect (30). A promising new development is probiotic therapy, or the use of colonizing bacteria with beneficial effects. In three human trials, including a multicenter European trial in infants (31), administration of probiotics, such as Lactobacillus rhamnosis GG and Lactobacillus reuterii, have been shown to reduce the severity and duration of diarrhea. However, at the present time, these products are expensive, costing about $\$ 0.70$ per capsule $\left(10^{10}\right.$ organisms), which is added to each 8 -oz. bottle of oral rehydration. This would cost about $\$ 2.80 / \mathrm{d}$ when added to maintenance fluids in a $10-\mathrm{kg}$ infant. BSC is available as a dietary supplement under the brand name ingredient Immunolin. The dietary supplement available in health food stores has had albumin removed, yielding a product that is $40 \%$ $\mathrm{IgG}$, making it about 2.5 -fold as rich in $\mathrm{IgG}$ as $\mathrm{BSC}$. The efficacy of BSC is most likely determined by its growth factors; therefore, the optimal dose for treatment of cryptosporidial enteritis remains to be determined. The cost of BSC is relatively low, $\$ 0.02$ to $\$ 0.07$ per gram $(\$ 0.20-\$ 0.70 / \mathrm{d}$ in a $10-\mathrm{kg}$ child), compared with other alternatives such as probiotics.
Depending on dose and efficacy, BSC is a promising new ingredient for bowel recovery.

The supply of BSC is substantial, particularly in countries with bovine-based protein consumption. The BSC used for these studies was processed and produced under USDA regulations for meat-based food ingredients. It is approved and is safe for use in foods. Despite the recent concerns in regard to bovine spongiform encephalopathy in Europe, no cases of bovine spongiform encephalopathy have been reported in the United States. Our data do not support the conclusion that BSC antibodies are protective, only that BSC facilitates bowel recovery.

In summary, oral BSC treatment, compared with soy protein supplementation, of newborn calves with cryptosporidial diarrhea reduced peak diarrheal volume, improved intestinal permeability, and facilitated crypt cell-mediated regeneration of villous surface. These significant effects and the low cost of BSC suggest that BSC should be studied in human trials of cryptosporidial diarrhea.

Acknowledgments. The authors thank Dr. Robert Bagnell for use of the University of North Carolina Department of Pathology microscopy services and Marjorie Gray for technical assistance.

\section{REFERENCES}

1. Scott CB, Sith HV, Mtambo MM, Gibbs HA 1995 An epidemiological study of Cryptosporidium parvum in two herds of adult beef cattle. Vet Parasitol 57:277-288

2. Angus KW 1983 Cryptosporidiosis in man, domestic animals and birds: a review. J R Soc Med 76:62-70

3. MacKenzie WR, Hoxie NJ, Proctor ME, Gradus MS, Blair KA, Peterson DE, Kazmierczak JJ, Addiss DG, Fox KR, Rose JB 1994 A massive outbreak in Milwaukee of cryptosporidium infection transmitted through the public water supply. N Engl J Med 331:161-167

4. Argenzio RA, Armstrong M, Rhoads JM 1996 Role of the enteric nervous system in piglet cryptosporidiosis. J Pharm Exp Ther 279:1109-1115

5. Ahdieh N, Blikslager AT, Bhat BG, ColemN RA, Argenzio RA, Rhoads JM 1998 L-Glutamine and transforming growth factor- $\alpha$ enhance recovery of monoacylglycerol acyltransferase and diacylglycerol acyltransferase activity in porcine postischemic ileum. Pediatr Res 43:227-233

6. Blikslager AT, Rhoads JM, Roberts MC, Bristol DG, Argenzio RA 1999 Glutamine and TGF-alpha stimulate extracellular regulated kinases and enhance recovery of villous surface area in porcine ischemic-injured intestine. Surgery 125:186-194

7. Lembcke JL, Peerson JM, Brown KH 1997 Acceptability, safety, and digestibility of spray-dried bovine serum added to diets of recovering malnourished children. J Pediatr Gastroenterol Nutr 25:381-384

8. Rhoads JM, Argenzio RA, Chen W, Fu Q, Weaver E, Graves LM 2000 L-Arginine (ARG) and serum stimulate intestinal restitution by distinct signaling pathways. Gastroenterology 118:A825(abstr)

9. Uden P, Colucci PE, Van Soest PJ 1980 Investigation of chromium, cerium, and cobalt as markers in digesta. Rate of passage studies. J Sci Food Agric 31:625-632

10. Argenzio RA, Liacos JA, Levy ML, Meuten DJ, Lecce JG, Powell DW 1990 Villous atrophy, crypt hyperplasia, and impaired glucose-Na absorption in enteric porcine cryptosporidiosis. Gastroenterology 98:1129-1140

11. Rhoads JM, Keku EO, Quinn J, Woosely J, Lecce JG 1991 L-Glutamine stimulates jejunal sodium and chloride absorption in pig rotavirus enteritis. Gastroenterology 100:683-691

12. Heijbel H, Slaine K, Seigel B, Wall P, McNabb SJN, Gibbins W, Istre G 1987 Outbreak of diarrhea in a day care center with spread to household members: the role of Cryptosporidium. Pediatr Infect Dis J 6:532-535

13. Greenberg PD, Cello JP 1996 Treatment of severe diarrhea caused by Cryptosporidium parvum with oral bovine immunoglobulin concentrate in patients with AIDS. J Acquired Immune Defic Synd Human Retrovirol 13:348-354

14. Naciri M, Lefay MP, Mancassola R, Poirier P, Chermette R 1999 Role of Cryptosporidium parvum as a pathogen in neonatal diarrhoea complex in suckling and dairy calves in France. Vet Parasitol 85:245-257

15. Crabb JH 1998 Antibody-based immunotherapy of cryptosporidiosis. Adv Parasitol 40:121-149

16. Jiang R, Chang X, Stoll B, Ellis KJ, Shypailo RJ, Weaver E, Campbell J, Burrin DG 2000 Dietary plasma protein is used more efficiently than extruded soy protein for lean tissue growth in early-weaned pigs. J Nutr 130:2016-2019 
17. Businco L, Bruno G, Giampietro PG, Cantani A 1992 Allergenicity and nutritional adequacy of soy protein formulas. J Pediatr 121:S21-S28

18. Erikson PS, Schauff DJ, Murphy MR 1989 Diet digestibility and growth of holstein calves fed acidified milk replacers containing soy protein concentrate. J Dairy Sci $72: 1528-1533$

19. Dawson DP, Morrill JL, Reddy PG, Minocha HC, Ramsey HA 1988 Soy protein concentrate and heated soy flours as protein sources in milk replacer for preruminant calves. J Dairy Sci 71:1301-1309

20. Rump JA, Arndt R, Arnold A, Bendick C, Dichtelmuller H, Franke M, Helm EB Jager H, Kampmann B, Kolb P, et al 1992 Treatment of diarrhea in human immunodeficiency virus-infected patients with immunoglobulins from bovine colostrum. Clin Investigator 70:588-594

21. Saxon A, Weinstein W 1987 Oral administration of bovine colostrum anticryptosporidia antibody fails to alter the course of human cryptosporidiosis. J Parasitol 73:413-415

22. Peeters JE, Villacorta I, Vanopdenbosch E, Vandergheynst D, Naciri M, AresMazas E, Yvore P 1992 Cryptosporidium parvum in calves: kinetics and immunoblot analysis of specific serum and local antibody responses (immunoglobulin $\mathrm{A}(\mathrm{IgA}), \operatorname{IgG}$, and $\operatorname{IgM})$ after natural and experimental infections. Infect Immun 60:2309-2316

23. Harrell RJ, Moon HK, Weaver EM, Campbell JM, Arthington JA, Odle J 2000 Effects of animal plasma proteins on intestinal recovery of neonatal pigs infected with rotavirus. FASEB J 14:A728(abstr)

24. Robinson P, Okhuysen PC, Chappell CL, Lewis DE, Shahab I, Lahoti S, White C 2000 Transforming growth factor beta1 is expressed in the jejunum after experimental Cryptosporidium parvum infection in humans. Infect Immun 68:5405-5407
25. Roche JK, Martins CAP, Cosme R, Fayer R, Guerrant RL 2000 Transforming growth factor beta-1 ameliorates intestinal epithelial barrier disruption by Cryptosporidium parvum in the absence of mucosal $\mathrm{T}$ lymphocytes. Infect Immun 68:5635-5644

26. Rhoads JM, Gomez GG, Chen W, Goforth R, Argenzio RA, Neylan MJ 1996 Can a "super" oral rehydration solution ("super ORS") stimulate intestinal repair in acute viral enteritis? J Diarrhoeal Dis Res 14:175-181

27. Donovan SM, Zijlstra RT, Odle J 1994 Use of piglet to study the role of growth factors in neonatal intestinal development. Endocr Regul 28:153-162

28. Rhoads JM, Lecce JG, Keku EO, Kandil H, Woodard PW, Chen W, Liu SC, Fuller CR, Leary HL, Ulshen MH 1995 Transforming growth factor-alpha stimulates jejunal mucosal recovery in piglet rotavirus enteritis. Pediatr Res 38:173-181

29. Gore SM, Fontaine O, Pierce NF 1992 Impact of rice based oral rehydration solution on stool output and duration of diarrhoea: meta-analysis of 13 clinical trials. BMJ 304:287-291

30. Bhan MK, Mahalanabis D, Fontaine O, Pierce NF 1994 Clinical trials of improved oral rehydration salt formulations: a review. Bull World Health Organ 72:945955

31. Guandalini S, Pensabene L, Zikri MA, Dias JA, Casali LG, Hoekstra H, Kolacek S, Massar K, Micetic-turk D, Papadopoulou A, deSousa JS, Sandhu B, Szajewska H, Weizman Z 2000 Lactobacillus GG administered in oral rehydration solution to children with acute diarrhea; a multicenter European trial. J Pediatr Gastroenterol Nutr 30:54-60

32. Dahlqvist A, Lindberg T (1966) Development of the intestinal disaccharidase and alkaline phosphatase activities in the human foetus. Clin Sci 30:517-528 